Manuscript prepared for Atmos. Chem. Phys. Discuss.

with version 3.5 of the $\mathrm{AT}_{\mathrm{E}} \mathrm{X}$ class copernicus_discussions.cls.

Date: 1 August 2012

\title{
Electronic supplement: Aerosol pollution potential from major population centers
}

D. Kunkel ${ }^{1}$, H. Tost $^{2}$, and M. G. Lawrence ${ }^{1, *}$

${ }^{1}$ Max Planck Institute for Chemistry, PO Box 3020, 55020 Mainz, Germany "now at: Institute for Advanced Sustainability Studies, 14467 Potsdam, Germany

${ }^{2}$ Johannes-Gutenberg University, Institute for Atmospheric Physics, 55099 Mainz, Germany

Correspondence to: Daniel Kunkel (daniel.kunkel@mpic.de)

\section{Introduction}

This file contains the electronic supplement for:

Kunkel et al (2012): Aerosol pollution potential from major population centers

2 Supplement to: Agricultural and population data 

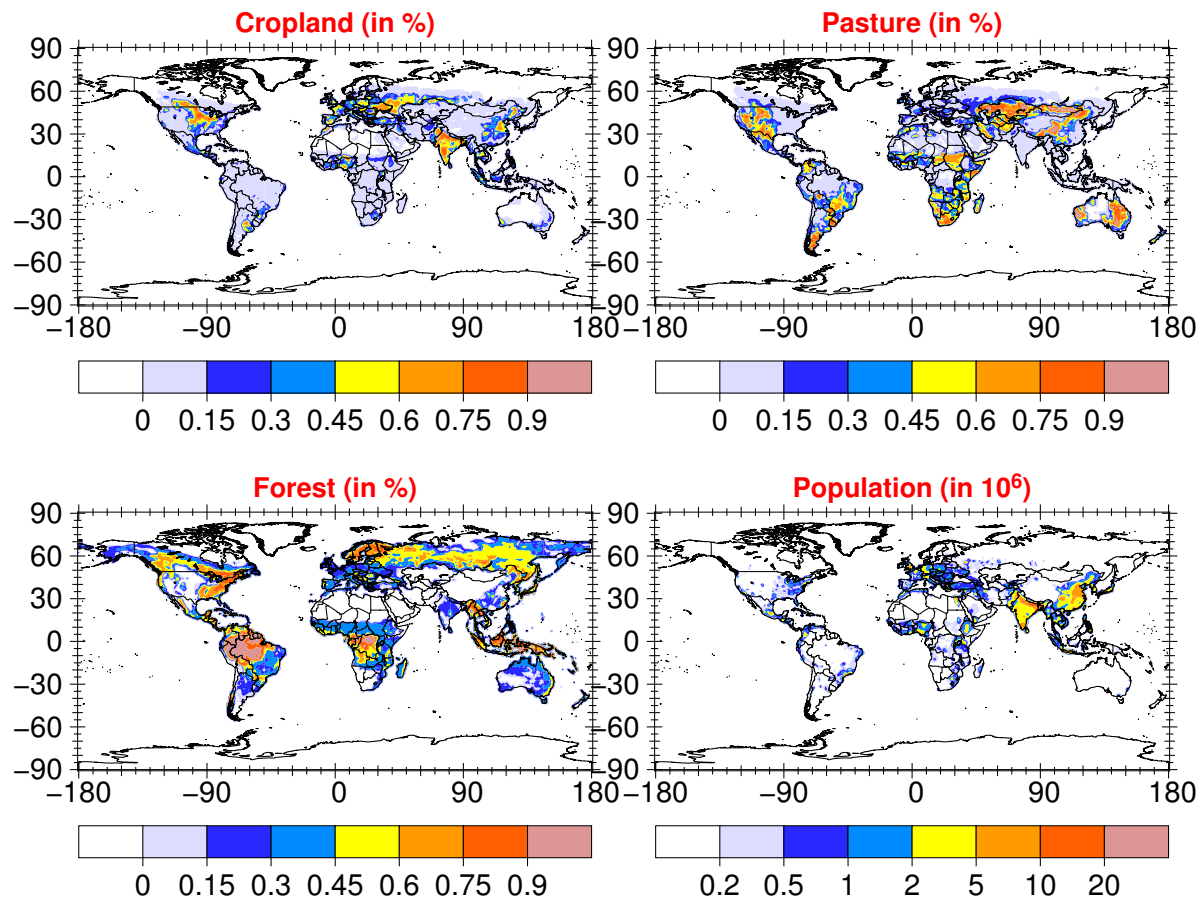

Fig. 1. Fraction of the area covered with crop land (upper left), pasture (upper right) and forest (lower left) in \%. Population number for the year 2005 in $10^{6}$ person/box (lower right).

\section{Supplement to model comparison of outflow characteristics from major population centers}

We use the same 36 major population centers as in L07 to test the reproducibility of their results. For this we applied EMAC in a setup comparable to the setup of L07 who used the semi-offline, 
three dimensional, chemical transport model MATCH-MPIC (e.g., Rasch et al., 1997; Lawrence et al., 1999; Kuhlmann et al., 2003). EMAC calculates its own meteorology and is nudged towards meteorological fields from ECMWF in this study whereas MATCH-MPIC relies on a limited set of meteorological input fields, i.e., surface pressure, geopotential, temperature, hor-

5 izontal winds, surface latent and sensible heat fluxes as well as zonal and meridional wind stresses from NCEP/NCAR reanalysis data (Kalnay et al., 1996) for every six hours. These variables are interpolated in time to the model time step of 30 minutes, and are used to diagnose online the transport by advection, deep convection, vertical diffusion, and also the hydrological cycle, i.e., water vapor transport, cloud condensate formation, and precipitation. A horizontal 10 resolution of $1.9^{\circ} \times 1.9^{\circ}$ in latitude and longitude, corresponding to T63 with 28 vertical sigma levels was applied from the surface up to $2 \mathrm{hPa}$. To obtain higher accordance in the model setup, EMAC was run in T63 but with 31 hybrid sigma levels in the vertical from the surface up to $10 \mathrm{hPa}$ with a model time step of 15 minutes. Both models rely on different physical parametrizations, e.g., for convection or advection tracer transport algorithms, but on the same 15 convective tracer transport scheme (Lawrence and Rasch, 2005). The main differences between the two models are summarized in Table 1. Furthermore, as 1995 was the year of analysis in L07, we also use the year 1995 for analysis which is "neutral" with regards to ENSO. In both models a passive gas phase tracer was released with a continuous and constant emission rate of $1 \mathrm{kgs}^{-1}$ in each box hosting one of the 36 MPCs.

20 On the left side in Figure 2 we apply the same color-scale to the EMAC data as L07 did in their Figure 1 (right side of Figure 2). The total column densities look similar in both simulations with only slight differences in the outflow from East Asia over the Pacific Ocean. A large part of the tracer mass in this outflow originates in the Indian subcontinent where convective mass fluxes at $850 \mathrm{hPa}$ and $700 \mathrm{hPa}$ are stronger in EMAC leading to a stronger upward transport 25 of tracer mass. Contrary, the burden in the outflow region from eastern South America over the southern Atlantic Ocean is smaller in the EMAC simulation as convective mass fluxes are higher in the MATCH-MPIC simulation in this region. However, the lifting of tracer mass out of the lowest layers is generally stronger in EMAC and consequently the surface densities in MATCHMPIC simulations are higher, although the surface layer is slightly deeper for MATCH-MPIC 
with about $80 \mathrm{~m}$ in contrast to about $60 \mathrm{~m}$ in case of EMAC.

We further apply the metrics $E L R_{1 \mathrm{~km}}, E_{\mathrm{UT}}$ and $A_{10}$ to our model data and compare it to the results reported in L07. Figure 3 shows the corresponding scatter plot of the three metrics for each major population center. A fairly good agreement is achieved for all three metrics which 5 is supported by high coefficients of determination $\left(R^{2}\right.$, based on the Pearson correlation coefficient) of $0.78\left(E L R_{1 \mathrm{~km}}\right), 0.72\left(E_{\mathrm{UT}}\right)$ and $0.75\left(A_{10}\right)$. The explanation of missing variance (about one quarter) is attributable to uncertainties in the underlying meteorological fields as well as model uncertainties, e.g., parametrizations for sub-grid scale processes or errors introduced by the numerical representation of physical equations.

10 Moreover, Table 2 provides a city by city listing of differences in the annual mean of the metrics, $E L R_{1 \mathrm{~km}}, E_{\mathrm{UT}}$ and $A_{10}$, and in the calculated ranks of each MPC. On average metrics calculated from MATCH-MPIC simulations show larger low-level outflow (negative mean in $E L R_{1 \mathrm{~km}}$ ) and a larger area with a mass threshold exceedance of $10 \mathrm{ng} \mathrm{m}^{-3}$ (negative mean in $A_{10}$ ) while the upper tropospheric pollution $E_{\mathrm{UT}}$ is larger in EMAC. Often a change for an MPC 15 in low-level pollution is accompanied by a change in upper level pollution of opposite sign. In addition, these results are consistent with findings in Figure 2 that in the case for EMAC simulations the ventilation of the boundary layer is stronger than for MATCH-MPIC due to generally more vertical transport. Maximum changes for $E L R_{1 \mathrm{~km}}$ are found for Moscow with $-11 \%$ and $+3.1 \%$ for Rio de Janeiro while most MPCs range between $-1.0 \%$ and $-6.0 \%$. Changes in $20 \quad E_{\mathrm{UT}}$ cover a broad range with $16 \%$ more mass above $5 \mathrm{~km}$ in MATCH-MPIC results for Rio de Janeiro while Mumbai has about $14 \%$ more mass in the upper troposphere in the EMAC results. For $A_{10}$ there is one outlier, Moscow, which shows a larger difference of $5.9 \times 10^{6} \mathrm{~km}^{2}$ while most other cities do not differ more than $2.7 \times 10^{6} \mathrm{~km}^{2}$.

In general, the main results from L07 are well reproduced when using EMAC which under25 lines the robustness of the results. The metrics mainly depend on the underlying meteorological fields and advective and convective transport schemes, which introduce the largest uncertainties in such calculations. 

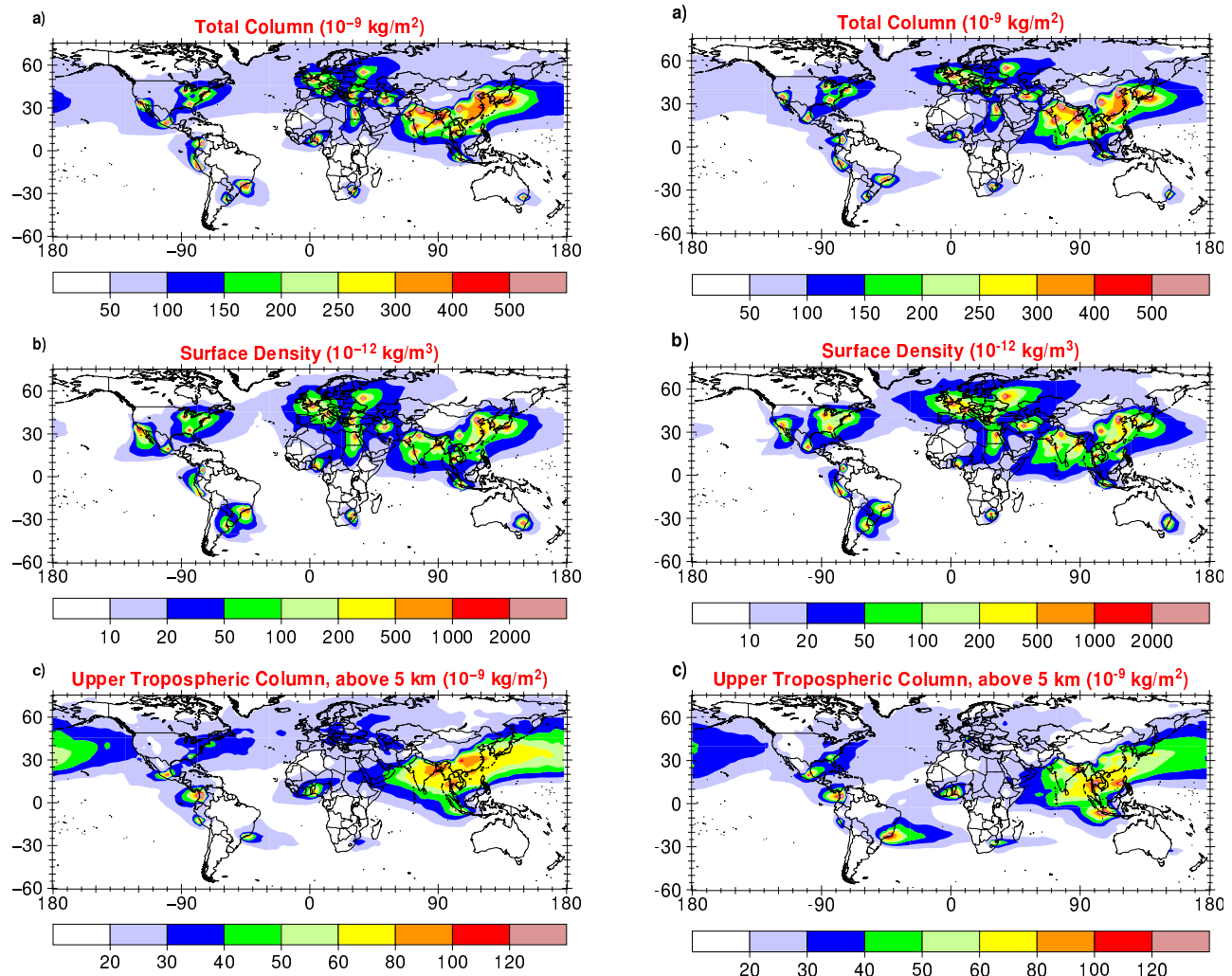

Fig. 2. Annual mean sum for a) the total column density in $10^{-9} \mathrm{~kg} \mathrm{~m}^{-2}$, b) the surface density in $10^{-12} \mathrm{kgm}^{-2}$, and c) upper tropospheric column above $5 \mathrm{~km}$ in $10^{-9} \mathrm{kgm}^{-2}$. On the left for EMAC simulations, on the right adopted from Lawrence et al. (2007), copyright 2007 by the European Geophysical Union. 
Table 1. Differences in model setup between EMAC and MATCH-MPIC.

\begin{tabular}{lll}
\hline & EMAC & MATCH-MPIC \\
\hline Vertical levels & 31 & 28 \\
Uppermost level ends at & $10 \mathrm{hPa}$ & $2 \mathrm{hPa}$ \\
Meteorological data & ECMWF & NCEP/NCAR reanalysis data \\
Coupling & online & semi-offline \\
Time step & $15 \mathrm{~min}$ & $30 \mathrm{~min}$ \\
Advection & Lin and Rood (1996) & Rasch and Lawrence (1998) \\
Convection & Tiedtke (1989) & Zhang and McFarlane (1995) \\
& Nordeng (1994) & Hack (1994) \\
\hline
\end{tabular}




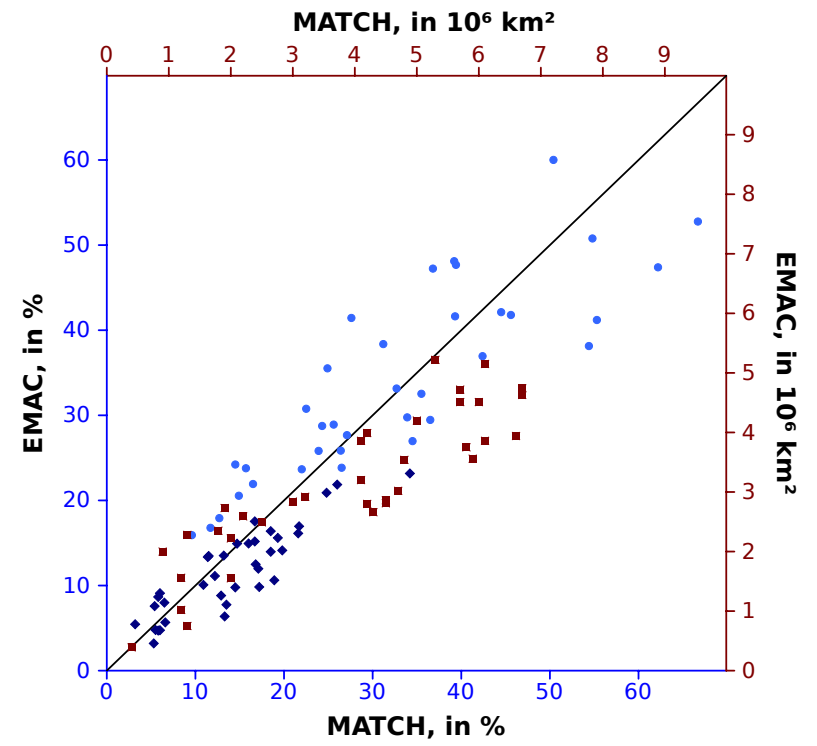

Fig. 3. Scatter plot of $E L R_{1 \mathrm{~km}}$ (dark blue diamonds), $E_{\mathrm{UT}}$ (light blue dots), and $A_{10}$ (red squares) obtained from EMAC (ordinate) and MATCH-MPIC (abscissa) data. 


\section{Seasonal metrics for the aerosol outflow}
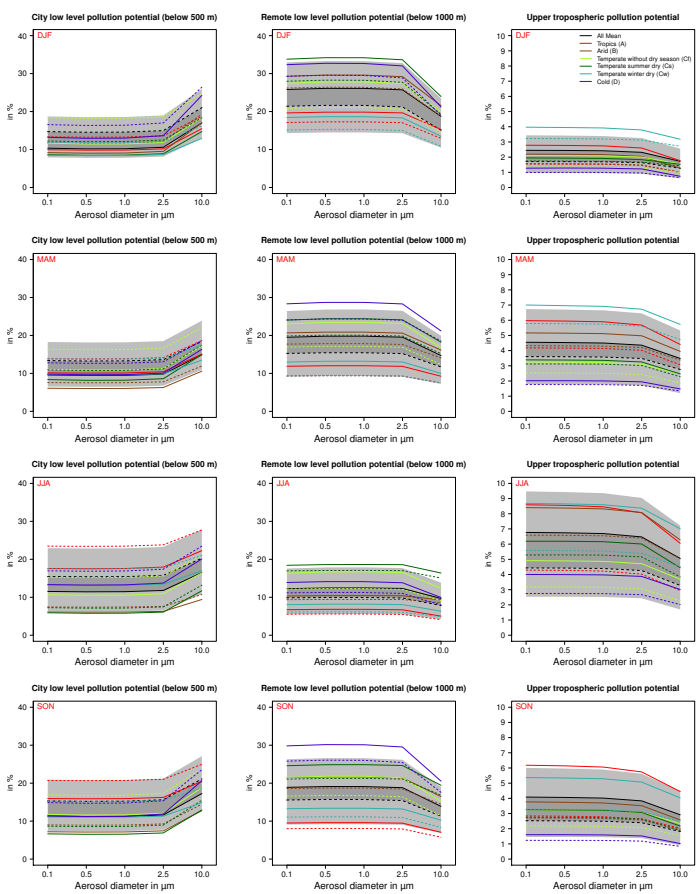

Fig. 4. Seasonal means of $E L R_{1 \mathrm{~km}}$ (left panels), $E_{\mathrm{UT}}$ (middle panels) and $R C L_{0.5 \mathrm{~km}}$ (left panels) for winter (DJF), spring (MAM), summer (JJA) and autumn (SON) from top to bottom. Results from the Southern Hemisphere have been shifted by six months to be in accordance with the Northern Hemispheric seasonal cycle. Colors indicate the region of the averaging: all MPCs (black), tropical (red), arid (brown), temperate no dry (light green), temperate summer dry (dark green), temperate winter dry (light blue), and cold (blue). Dashed lines represent $\mathrm{NS}_{\text {act }}$, solid lines $\mathrm{NS}_{\text {inact }}$ averages. 
Table 2. Differences between EMAC and MATCH-MPIC annual values and corresponding ranks for $E L R_{1 \mathrm{~km}}, E_{\mathrm{UT}}$, and $A_{10}$ for the 36 MPCs: $\bar{x}$, mean differences; $x_{d}$, corresponding mean absolute deviations, with $\bar{x}=\sum_{i=1}^{N} x_{i} / N, x_{d}=\sum_{i=1}^{N}\left|x_{i}^{\prime}\right| / N, x_{i}^{\prime}=x_{i}-\bar{x}, x_{i}$ metric value of an MPC, and $N$ total number of MPCs.

\begin{tabular}{|c|c|c|c|c|c|c|}
\hline & $\begin{array}{c}E L R_{1 \mathrm{~km}} \\
\%\end{array}$ & Rank & $\begin{array}{c}E_{\mathrm{UT}} \\
\%\end{array}$ & Rank & $\begin{array}{c}A_{10} \\
\times 10^{6} \mathrm{~km}^{2}\end{array}$ & Rank \\
\hline \multicolumn{7}{|l|}{ Europe } \\
\hline London & -4.14 & 0 & 5.08 & 0 & -2.07 & 4 \\
\hline Paris & -3.9 & 0 & 5.22 & 0 & -1.96 & 1 \\
\hline Moscow & -11.03 & 0 & 6.32 & 0 & -5.92 & 1 \\
\hline Po Valley & -2.11 & -4 & 5.43 & 2 & -0.8 & -4 \\
\hline Istanbul & -4.74 & 1 & 5.65 & 1 & -0.98 & -6 \\
\hline \multicolumn{7}{|l|}{ West Asia } \\
\hline Teheran & -7.37 & 11 & 8.08 & -1 & -1.64 & 7 \\
\hline \multicolumn{7}{|l|}{ Africa } \\
\hline Cairo & -5.47 & 2 & 9.72 & -5 & -0.95 & -2 \\
\hline Lagos & -1.25 & 5 & -2.38 & 0 & 1.1 & -4 \\
\hline Johannesburg & 1.49 & -1 & -5.45 & 6 & 0.36 & -2 \\
\hline \multicolumn{7}{|l|}{ Southern Asia } \\
\hline Karachi & -5.12 & 6 & 8.27 & -9 & -1.19 & -3 \\
\hline Mumbai & -4.72 & 5 & 13.84 & -9 & -1.68 & 3 \\
\hline Delhi & -8.28 & 12 & 10.62 & -9 & -2.66 & 7 \\
\hline Kolkata & -5.75 & 9 & 10.44 & -6 & -1.26 & 2 \\
\hline Dhaka & -6.93 & 10 & 8.91 & -8 & -1.69 & 6 \\
\hline \multicolumn{7}{|l|}{ Eastern Asia } \\
\hline Szechuan Basin & -1.09 & 4 & 8.28 & -5 & -0.55 & 4 \\
\hline Beijing & -5.67 & 6 & 4.45 & -3 & -2.34 & 7 \\
\hline Tianjin & -4.53 & 4 & 3.31 & -2 & -2.24 & 7 \\
\hline Shanghai & -4.31 & 4 & 0.45 & -1 & -1.49 & 1 \\
\hline Seoul & -1.52 & -6 & 0.57 & 3 & -0.21 & -10 \\
\hline
\end{tabular}


Table 2. continued

\begin{tabular}{lcccccc} 
Tokyo & 1.97 & -9 & -7.04 & 7 & 0.39 & 0 \\
Osaka & 0.32 & -7 & -4.14 & 3 & -0.28 & -4 \\
Hong Kong/PRD & -4.08 & 3 & 2.33 & -1 & -1.64 & 3 \\
Southeast Asia & & & & & & \\
Manila & 2.86 & -6 & -14.81 & 4 & 0.83 & -5 \\
Bangkok & -0.93 & 4 & -4.02 & -1 & -0.45 & 5 \\
Jakarta & 2.25 & -4 & -13.93 & 1 & 0.98 & -3 \\
Australia & & & & & & \\
Sydney & 1.95 & -9 & -7.53 & 9 & -0.01 & 2 \\
North America & & & & & & \\
Chicago & -3.7 & 1 & 1.92 & 0 & -2.05 & 5 \\
New York & -1.06 & -6 & -0.55 & 3 & -0.9 & -4 \\
Los Angeles & 0.84 & -10 & 1.66 & 2 & -0.08 & -11 \\
Atlanta & -1.08 & -4 & -2.97 & 3 & -1.4 & 4 \\
Mexico City & -0.72 & 0 & -3.81 & 2 & -0.18 & 1 \\
South America & & & & & & \\
Bogotá & -2.1 & 1 & 9.61 & -5 & -0.01 & 0 \\
Lima & -0.82 & -5 & 7.17 & -6 & -0.16 & -3 \\
Rio de Janeiro & 3.1 & -6 & -16.26 & 9 & 0.55 & -2 \\
São Paulo & 2.18 & -5 & -14.1 & 9 & 0.22 & 3 \\
Buenos Aires & 0.22 & -6 & -2.66 & 7 & -0.24 & -10 \\
\hline$x$ & -2.32 & 0 & 1.05 & 0 & -0.91 & 0 \\
$x_{d}$ & 2.88 & 4.89 & 6.41 & 3.94 & 0.99 & 4.06 \\
\hline
\end{tabular}




\section{Supplement to: Impact of high concentrated deposition on ecosystem}
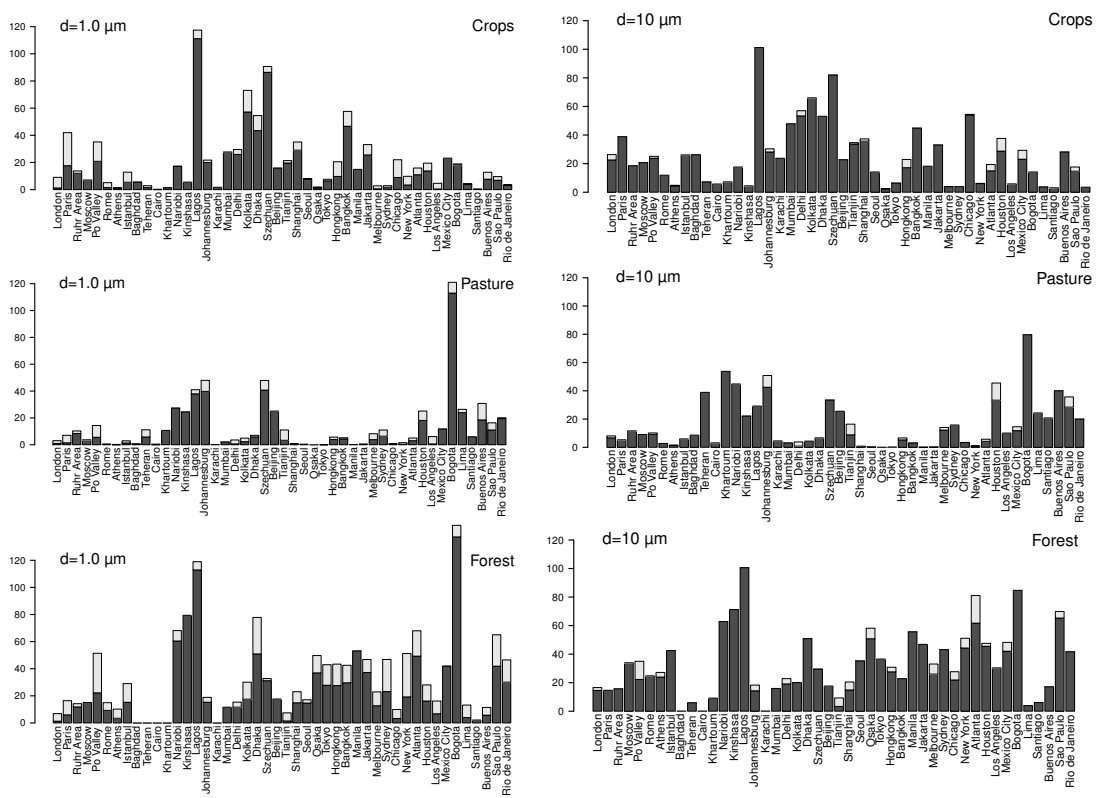

Fig. 5. Crop land, pasture, and forest areas covered with at least $1 \%$ of the emission of an MPC $\left(D_{1}\right)$ for $1.0 \mu \mathrm{m}$ (left) and $10.0 \mu \mathrm{m}$ (right) aerosol tracers. Dark gray bars show the minimum area covered by either the $\mathrm{NS}_{\text {act }}$ or $\mathrm{NS}_{\text {inact }}$ tracers, light gray bars show the additional area by the tracer with the other NS state.

\section{References}

Hack, J. J.: Parameterization of moist convection in the National Center for Atmospheric Research community climate model (CCM2), Journal of Geophysical Research, 99, PP. 5551-5568, doi: 
199410.1029/93JD03478, 1994.

Kalnay, E., Kanamitsu, M., Kistler, R., Collins, W., Deaven, D., Gandin, L., Iredell, M., Saha, S., White, G., Woollen, J., Zhu, Y., Leetmaa, A., Reynolds, R., Chelliah, M., Ebisuzaki, W., Higgins, W., Janowiak, J., Mo, K. C., Ropelewski, C., Wang, J., Jenne, R., and Joseph, D.: The NCEP/NCAR 40-Year Reanalysis Project, Bulletin of the American Meteorological Society, 77, 437-471, doi:10. 1175/1520-0477(1996)077〈0437:TNYRP $\rangle$ 2.0.CO;2, 1996.

Kuhlmann, R. v., Lawrence, M. G., Crutzen, P. J., and Rasch, P. J.: A model for studies of tropospheric ozone and nonmethane hydrocarbons: Model description and ozone results, Journal of Geophysical Research, 108, 22 PP, 2003.

Lawrence, M. G. and Rasch, P. J.: Tracer Transport in Deep Convective Updrafts: Plume Ensemble versus Bulk Formulations, J. Atmos. Sci., 62, 2880-2894, doi:10.1175/JAS3505.1, 2005.

Lawrence, M. G., Crutzen, P. J., Rasch, P. J., Eaton, B. E., and Mahowald, N. M.: A model for studies of tropospheric photochemistry: Description, global distributions, and evaluation, Journal of Geophysical Research, 104, 26,245-26,277, 1999.

Lin, S. and Rood, R. B.: Multidimensional Flux-Form Semi-Lagrangian Transport Schemes, Monthly Weather Review, 124, 2046-2070, doi:10.1175/1520-0493(1996)124〈2046:MFFSLT〉2.0. $\mathrm{CO} ; 2,1996$.

Nordeng, T.: Extended versions of the convective parametrization scheme at ECMWF and their impact on the mean and transient activity of the model in the tropics, Technical memorandum, ECMWF, Reading, UK, 1994.

Rasch, P. J. and Lawrence, M.: Recent developments in transport methods at NCAR, Tech. Rep. 265, Hamburg, Germany, edited by B. Machenhauer, 1998.

Rasch, P. J., Mahowald, N. M., and Eaton, B. E.: Representations of transport, convection, and the hydrologic cycle in chemical transport models: Implications for the modeling of short-lived and soluble species, Journal of Geophysical Research, 102, PP. 28,127-28,138, doi:199710.1029/97JD02087, 1997.

Tiedtke, M.: A Comprehensive Mass Flux Scheme for Cumulus Parameterization in Large-Scale Models, Monthly Weather Review, 117, 1779-1800, 1989.

Zhang, G. and McFarlane, N. A.: Sensitivity of climate simulations to the parameterization of cumulus convection in the Canadian climate centre general circulation model, Atmosphere-Ocean, 33, 407446, doi:10.1080/07055900.1995.9649539, 1995. 